\title{
Deep Energy Retrofit of Residential Buildings in the Mediterranean Area: The MedZEB Approach
}

\author{
Roberta Capogrosso, Giulia De Aloysio, Luca Laghi, Roberto Malvezzi, \\ Eraldo Menconi, Marco Padula, Francesca Pecchia, Ángel Ruìz Cruceira, \\ José Manuel Salmeròn Lissén, and Paolo Luigi Scala
}

\begin{abstract}
Mediterranean deep retrofit markets are characterized by common barriers and bottlenecks, which barely have been identified as shared challenges, and this has led to a lack of dedicated solutions and to a substantial delay in achieving the 2020 EU policy targets. This situation is addressed by the H2020 HAPPEN project by proposing a new MedZEB approach characterized by the following features:
\end{abstract}

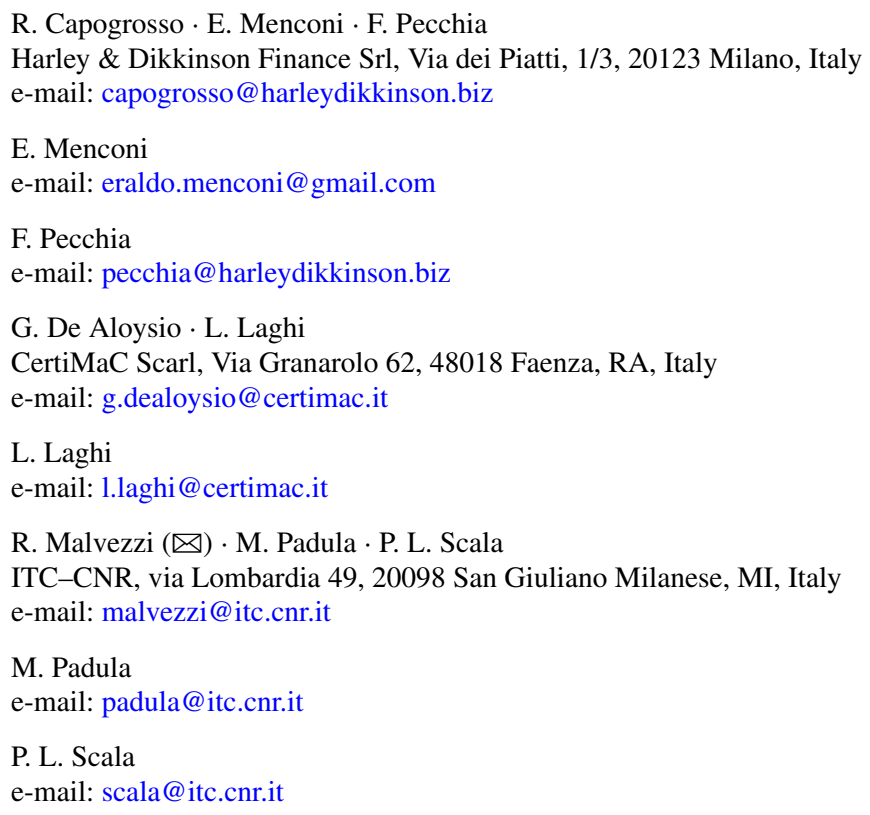

\section{Á. R. Cruceira · J. M. Salmeròn Lissén}

Escuela Superior de Ingeniería, Grupo de termotecnia Universidad de Sevilla Camino de Los Descubrimientos S/N, 41092 Sevilla, Spain

e-mail: arcruceira@us.es

J. M. Salmeròn Lissén

e-mail: jms@us.es 
- Holistic, i.e., aimed at integrating the most relevant aspects of the retrofitting supply chain;

- Transparent, i.e., aimed at putting on the market novel tools for enhancing investors' trust;

- Adaptive, i.e., aimed at enhancing "added values" of the retrofitting such as flexibility, well-being, etc.

Having arrived at its midpoint, HAPPEN has produced an advanced version of its main outputs, among which are:

- the HAPPEN cost-optimal technical solutions, developed according to a step-bystep logic;

- the HAPPEN financial solution, fully integrated with the step-by-step logic, and aimed at funding the retrofitting process by relying on the energy savings achieved;

- the MedZEB protocol conceived as a guarantee scheme for the achievement of retrofit targets;

- the HAPPEN platform, an assisted digital marketplace aimed at matching demand and offer according to a one-stop-shop logic, at defragmenting the retrofit value chain, and at supporting actors with dedicated tools.

These outputs have been developed also thanks to an extensive living laboratory and pilot-building program, carried out within ten pilot sites across seven EU Med countries; this has made it possible for a large engagement of potential users, which resulted in the ideation of the HAPPEN program, an overall framework aimed at integrating project outputs into an exploitable renovation procedure powered by the HAPPEN platform. This paper describes the first simulation of such a procedure in its entirety based on a real case study. After characterizing the building according to the HAPPEN reference buildings and climates lists, a step-by-step cost-optimal package of solutions was calculated, followed by the application of the HAPPEN financial solution, and by the draft issue of the MedZEB protocol. Results provide the first evidence of the effectiveness of the MedZEB approach in potentially unlocking the deep retrofit market in the Med area, with special attention to the possibility of funding the interventions by relying on the economies generated by the energy savings achieved. Further, the project activities will be aimed at co-creating, together with relevant stakeholders, a go-to-market strategy for the HAPPEN program.

Keywords MedZEB approach $\cdot$ MedZEB protocol $\cdot$ Cost-optimal holistic solutions $\cdot$ HAPPEN program $\cdot$ HAPPEN platform 


\section{Introduction and General Methodology}

This paper describes the first outcomes of an ongoing research and experimentation project, namely HAPPEN, ${ }^{1}$ aimed at boosting the market uptake of deep energy retrofitting of residential buildings within Mediterranean EU countries (Padula et al. 2018). As a matter of fact, the development of the deep retrofitting market (DRM) is facing difficulties throughout Europe, but in the Mediterranean (Med) space, these assume specific characteristics due to environmental and climatic factors, to the ownership structure, to the characters of the built stock, to peculiar social and economic conditions and to the consequences of the economic crisis. It is thus necessary to set up a strategy that goes beyond the physical needs of the buildings and technological issues for also integrating social, entrepreneurial, financial, regulative and environmental aspects, as means to deal successfully with the complexity of the Med living spheres, and with the behaviors of their communities. For this purpose, HAPPEN is developing a specific Med zero energy buildings approach(MedZEB), aimed at reconnecting the fragmented value chain, at enhancing trust, and at increasing the overall DRM convenience and appeal. The MedZEB approach features the following characteristics:

\begin{tabular}{l|l|l|l}
\hline Tailored & Transparent & Holistic & Adaptive \\
\hline $\begin{array}{l}\text { Med area (residential } \\
\text { sector) }\end{array}$ & HAPPEN platform & $\begin{array}{l}\text { Engagement and } \\
\text { training }\end{array}$ & $\begin{array}{l}\text { To persons: focus on } \\
\text { well-being }\end{array}$ \\
\cline { 4 - 4 } & & $\begin{array}{l}\text { To relations: living } \\
\text { laboratory methodology }\end{array}$ \\
\cline { 3 - 4 } & MedZEB protocol & $\begin{array}{l}\text { Financing and } \\
\text { regulation }\end{array}$ & $\begin{array}{l}\text { To resources: } \\
\text { step-by-step approach }\end{array}$ \\
\cline { 4 - 4 } & & $\begin{array}{l}\text { To situations: alternative } \\
\text { investment options }\end{array}$ \\
\cline { 3 - 4 } & & Optimal solutions & $\begin{array}{l}\text { To environment: district } \\
\text { scale design }\end{array}$ \\
\cline { 3 - 4 } & & $\begin{array}{l}\text { To context: smart } \\
\text { integration }\end{array}$ \\
\hline
\end{tabular}

The "transparency" of the approach is pursued through the following main tools:

A. The HAPPEN platform, an assisted digital marketplace aimed at matching demand and offer, at defragmenting the value chain, and at supporting renovation actors with dedicated tools.

B. The MedZEB protocol, a guarantee scheme for the good execution of the retrofitting process.

\footnotetext{
${ }^{1}$ HAPPEN-Holistic APproach and Platform for the deep renovation of the Med residential built ENvironment; H2020 grant n. 785072; Call EE-11-2017; duration: 04/2018-03/2021; LP: ITCCNR.
} 
The "holism" of the approach is pursued through the following main project pillars:

1. Engagement and training: a wide range of target groups (encompassing owners and inhabitants, building professionals, entrepreneurs, policy makers, etc.) were engaged in order to stimulate knowledge transfer and behavioral upgrade.

2. Optimal solutions: an extensive work of optimization of the available technologies has been carried out, in order to compose cost-optimal packages of solutions (POS) to be applied to different residential typologies according to a one-stop-shop and a step-by-step logic.

3. Financial and regulation: Basing on a review of available innovative financial solutions (i.e., guarantee and solidarity funds, credit transfer mechanisms, etc.), the HAPPEN financial solution has been developed, aimed at flexibly assisting the funding of the retrofitting process according to a staged approach fully integrated with the POS.

Research activities have been carried out within ten pilot sites in seven EU Med countries, where living laboratories have been activated, and pilot buildings have been identified, to gather requirements, feedbacks, beta-testing and fine-tuning, in view of the project outputs development.

\section{Insights from the Research}

Having arrived at the midpoint of its implementation, HAPPEN has delivered its main outputs in an advanced version; testing and fine-tuning within pilots will be carried out until the end of the project.

\subsection{Cost-Optimal Technical Solutions}

The methodology adopted is described in the amending EPBD (Directive 844/EU 2018). Global costs have been based on life cycle costs (LCC), and the primary energy consumption (PEC) has been calculated dynamically on an hourly basis by using a software complying with the BESTEST of the IEA. The same methodology has been used also in other references, like BPIE (2010), Brandao et al. (2016), Becchio et al. (2015). An extensive abacus of renovation measures has been produced, by gathering technical solutions country per country. A common climatic zoning for the EU area has also been developed, as well as a common abacus of reference buildings for the Med countries. This led to the calculation of 546 cost-optimal packages of solutions (42 reference buildings $\times 13$ reference climates) in total (Fig. 1). 


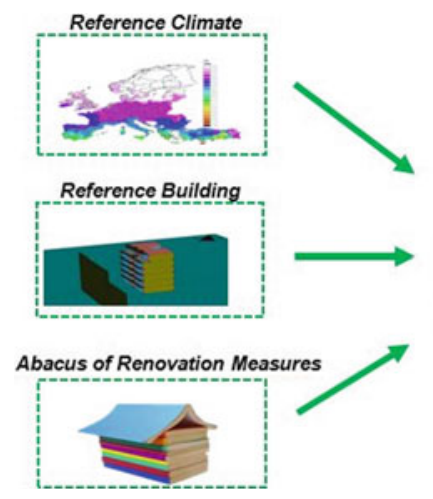

HAPPEN METHODOLOGY FOR MED AREA OPTIMAL PACKAGESOF SOLUTIONS

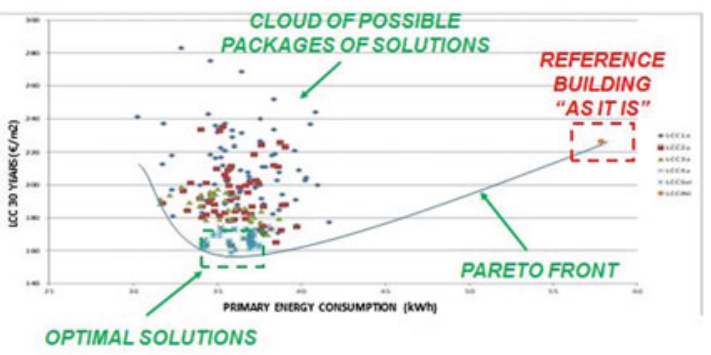

Fig. 1 Life cycle cost versus primary energy consumption for all the renovation measures analyzed per reference building and reference climate to identify the cost-optimal POS

\subsection{The HAPPEN Financial Solution}

The research was aimed at developing a new financial solution able to flexibly assist the deep retrofitting process according to a step-by-step approach, thus enabling taking into account unpredictable events occurring to the homeowners in the long run of a reimbursement plan (e.g., asset sale or inheritance, technological updates, fluctuation of energy costs, etc.). The research resulted in the development of the versatile energy loan (VEL) solution, which consists of a single mortgage arrangement (30-year basis) with multiple steps of disbursement, each one corresponding to the cost of the renovation steps. This feature makes possible a reduction of the initial mortgage (see Fig. 2), to the benefit of low-income or low-resources families, as well as for a full flexibility of the solutions, since the plan can be updated or interrupted after each step. Furthermore, the VEL solution is based on a fixed interest rate for the whole duration of the plan, which would enable taking advantage of the actual situation in the money market. Finally, the reimbursement plan would be shaped to be funded by the economies generated at each step by the energy savings achieved, thus allowing for the full financial sustainability of the interventions.

\subsection{The MedZEB Protocol}

The MedZEB protocol was designed and developed with the aim of incentivizing clients to invest in building retrofitting, by offering them a guarantee that the retrofitting process will be carried out properly along the whole value chain. Furthermore, the protocol contains the quality requirements necessary for accessing the HAPPEN financial solution (see Sect. 2.2), as well as specific KPIs addressing comfort, behavioral and well-being aspects (Fabbri 2016; Antonucci 2019).

The protocol includes also the following main documents: 


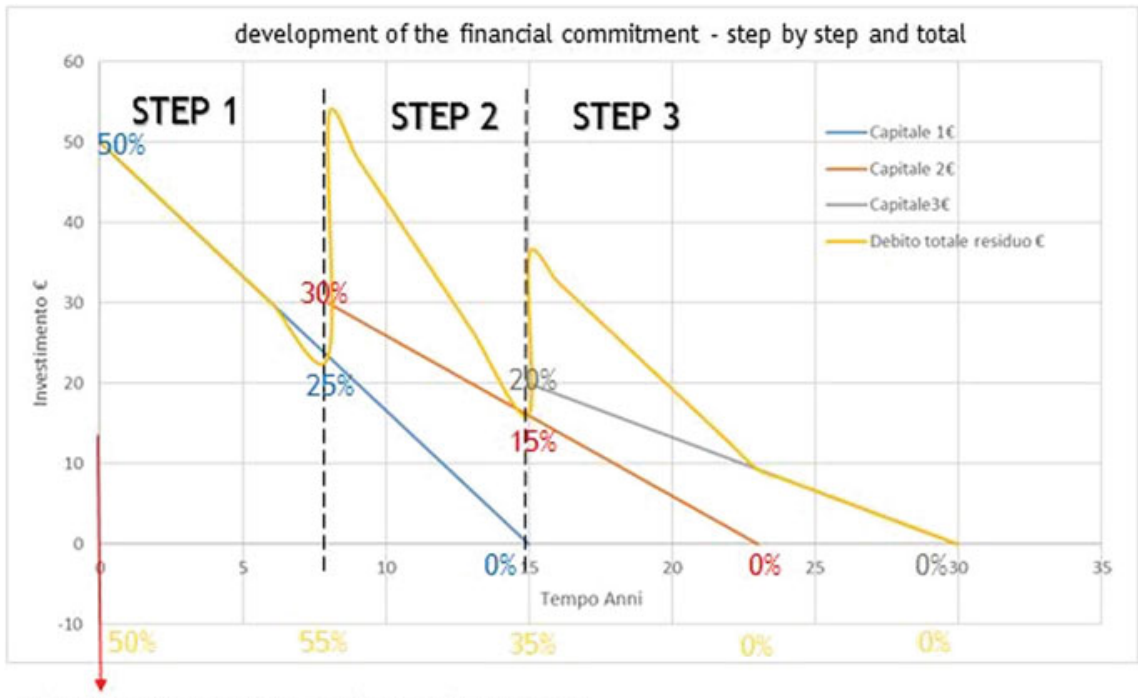

Single MORTGAGE registered at year 0

Fig. 2 General plan of the versatile energy loan on a three-step basis, with reimbursement in 30 years, $50 \%$ of the total investment concentrated in the first step and mortgage based on $50 \%$ of the total investment

- Energy Performance Certificate (EPC. BPIE 2014; Caceres and Diaz 2018);

- Preliminary Retrofitting Project, identifying the boundary conditions and the design objectives;

- Building Renovation Roadmap, describing the breakdown of the retrofitting project into steps;

- Business Plan, based on the HAPPEN financial solution;

- MedZEB Voluntary Certification Scheme (VCS).

The VCS will be issued at the end of each renovation step, after a positive assessment of the achievement of energy saving targets. For this reason, the MedZEB VCS entails a "relative," and not an "absolute," certification of the energy performance (see Fig. 3).

To this end, a monitoring process will be implemented after each renovation step, based on a dedicated monitoring protocol. In case, the assessment is not fully

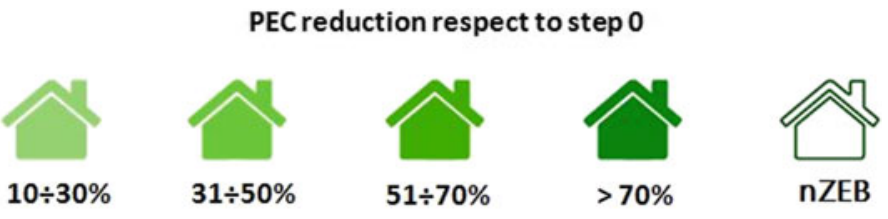

Fig. 3 General layout of the MedZEB Voluntary Certification Scheme 
positive, the guarantee framework of the protocol will be activated, leading to the definition of a contingency plan, the execution of which will be mandatory for the activation of the next step. The development of the MedZEB protocol was based on extensive literature research, including building environmental assessment methods (Triple E 2014; EnerPhit 2015; Kudryashova, Genkov and Mo 2015; Hamelman 2016; Asdrubali 2017; Mattoni 2018; Sesana and Salvalai 2018) and Building Passports running experiences (Sesana and Salvalai 2018; Fabbri 2016). The protocol was designed not only as a detailed, standardized and transparent tool, but also as a simple and cheap one to be used throughout the renovation process.

\subsection{The HAPPEN Program}

The outputs described above have been included into the "HAPPEN program", which is a comprehensive framework of actions, tools and services aimed at boosting the uptake of the MedZEB approach. The program is composed of three main stages:

1. Engaging phase: Potential clients (e.g., households and property owners) are engaged by offering them effective information on the opportunities offered by HAPPEN, as well as an easy-to-use tool for getting oriented on the potentialities related to their own building retrofitting.

2. Convincing phase: The engaged client is proposed to contact a MedZEB expert who is a trained professional responsible for the overall application of the MedZEB approach. The expert develops a feasibility retrofit study based on the HAPPEN technical and financial solutions.

3. Performing phase: If the convincing phase is successful, the expert produces a full retrofit design, and the MedZEB protocol is subscribed by all the actors involved in the process. Monitoring of results and the issue of the MedZEB VCS are then carried out after each renovation step.

\subsection{The HAPPEN Platform}

The HAPPEN platform is conceived as the main vehicle for the market uptake of the HAPPEN program. To this extent, it has been structured in order to support the program main stages with dedicated digital services, by providing different final user types (owners, makers and influencers) with a differentiated access to the HAPPEN outputs, according to their specific needs:

- Owners will access educational and awareness raising materials (e.g., e-pills, basic training, success stories, etc.) and a quick configurator for a first assessment of their savings potential (engaging phase).

- Makers will access relevant documents of the HAPPEN knowledge base and will have the opportunity to attend the MedZEBinars, the training course for 
becoming MedZEB experts. Furthermore, the experts will gain access to the "expert dashboard," which provides interactive data tables and tools for exploring and customizing the POS, for shaping VEL-based financial plans (convincing phase) and for elaborating the MedZEB protocol and VCS (performing phase).

- Influencers will access relevant documents of the HAPPEN knowledge base, as well as a dedicated dashboard for keeping track of retrofit market trends.

All groups will access digital forums where they will be enabled to interact among each other and to provide feedbacks on the MedZEB approach. In this way, the platform will act as an assisted marketplace, as an e-learning and services provider, and as a digital community for defragmenting the retrofitting supply and value chain, and it will aim to become the reference portal at EU level for the DRM in the Med area. To this extent, the platform has been co-designed with potential end-users thanks to their deep engagement in the HAPPEN Living Laboratories.

\section{Application to a Case Study}

The outputs described above have been tested on a real case study to verify their interoperability and to facilitate the assessment and fine-tuning of the research results. The case study is a multi-family building of 12 dwellings on six stories, inserted within a larger district block in Milan (IT). Geometry and U-values of the envelope are showed in Fig. 4 (for more details see Appendix §5.1). The total energy consumption per year is $176.5 \mathrm{kWh} / \mathrm{m}^{2}$ and the PEC per year is $187.7 \mathrm{kWh} / \mathrm{m}^{2}$, with 35.16 $\mathrm{kgCO}_{2} / \mathrm{m}^{2}$ of emissions on a yearly basis.

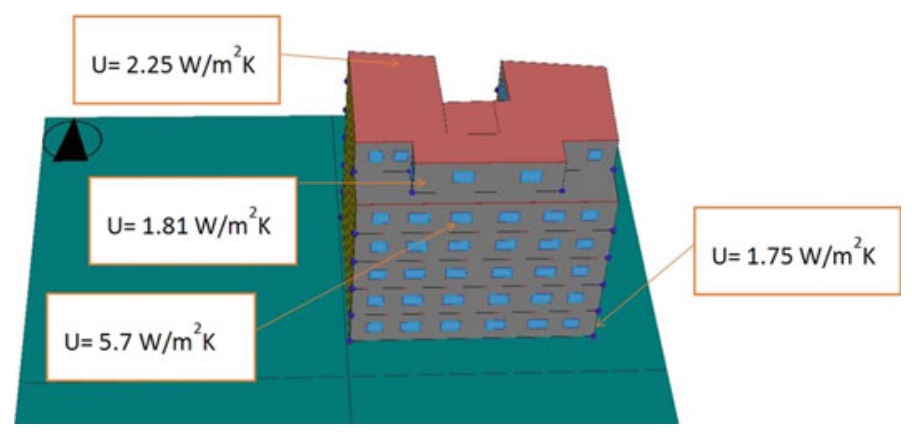

Fig. 4 Geometry and U-values of the case study building envelope 


\subsection{Application of Cost-Optimal Solutions}

The climate of Milan corresponds to the W2S2 HAPPEN climate scale (for more details see Appendix \$5.1). The building corresponds to the multi-family reference building typology "Italy 1980-2000." Costs for the renovation measures have been evaluated using the Milano Municipality price-list for public works. The POS identified for this case study, expressed in terms of minimizing the life cycle cost, is briefly described as follows (for more details see Appendix §5.2).

- Building envelope. Roof: eight $\mathrm{cm}$ of XPS insulation on the outdoor surface; windows: double glazing filled with argon; façades: ETICS with eight $\mathrm{cm}$ of EPS; air-tightness: in the contour joints of the new windows; thermal bridges: reduction of the external psi-value of slabs--façades junctions and window contours; and shadings: reduction of the solar factor by $50 \%$.

- Building systems. Controlled mechanical ventilation system (CMVS); heating: new condensing gas boiler; domestic hot-water system (DHWS) based on aerothermal technology (50\% RES).

- Building surroundings. According to the Solene project outputs for this typology of intervention, glazing ratio and level of insulation, the optimum solution is to plant trees along the street (Morille et al. 2015).

Because the whole intervention cost would be very high to be sustained in one step, also provided the large number of owners, a step-by-step approach has been defined. The inner constraints assumed for the definition of the steps are the following: Façades and thermal bridges related to façades are improved simultaneously; air-tightness and façades are improved together; windows and outside glass-doors are changed together; window renewal is associated with the improvement of thermal bridges on the windows contour; limited investment per step: $\max .144,000 €\left(120 € / \mathrm{m}^{2}\right.$ of useful surface). Basing on this, the POS has been divided into three steps (Fig. 5), the characteristics of which are the following (for more details see Appendix §5.3):

- Step 1: outdoor façades, windows and thermal bridges;

- Step 2: roof, CMVS, shading elements;

- Step 3: condensing gas boiler, DHWS (50\% RES).

\begin{tabular}{l|l|l|l|l}
\hline Step & Total cost & Yearly savings & Upgraded PEC & By steps PEC reduction (\%) \\
\hline 1 & $€ 132,996.37$ & $€ 8923.60$ & $146.2 \mathrm{kWh} / \mathrm{m}^{2}$ & 22 \\
\hline 2 & $€ 84,741.49$ & $€ 140,226.42$ & $82.36 \mathrm{kWh} / \mathrm{m}^{2}$ & 44 \\
\hline 3 & $€ 50,097.60$ & $€ 3903.60$ & $64.4 \mathrm{kWh} / \mathrm{m}^{2}$ & 22 \\
\hline
\end{tabular}

As final result, the PEC has been reduced from the initial value of $187.7 \mathrm{kWh} / \mathrm{m}^{2}$ to $64.4 \mathrm{kWh} / \mathrm{m}^{2}$, which implies a cumulative reduction of $\mathbf{6 6 \%}$, thus fulfilling the "deep retrofitting" standard $(>60 \%)$. The LCC reduction is from $806.9 € / \mathrm{m}^{2}$ to $304.1 € / \mathrm{m}^{2}$ of useful surface. Figure 5 graphs this evolution. 


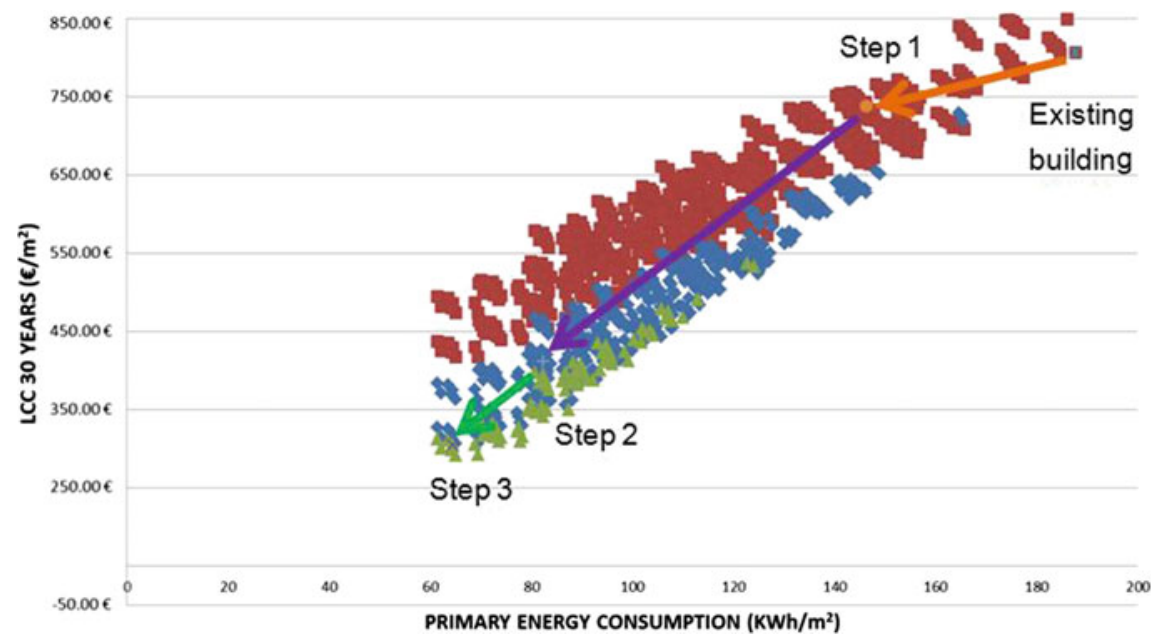

Fig. 5 PEC versus LCC diagram showing the clouds of solutions of the step-by-step renovation. Dots in red, blue and green are those considered for determining, resp., the first, the second and the third step

\subsection{Application of the Financial Solution}

The simulations have been carried out by assuming an interest rate at $3 \%$, and by introducing an excess approximation of the costs, as well as an efficiency decrease of the installation/envelope system, to test the robustness of the solution under stress conditions. The fiscal incentives available in Italy according to actual laws have also been considered (tax credit mechanism with $70 \%$ of reimbursement in ten years), but only for the first step, to cope with uncertainties on their future confirmation. Starting data and results of the simulation are the following (for more details see Appendix $\S 5.4)$;

- First step: reimbursement in eleven years.

- Second step: reimbursement in seven years from the date of the eight year of the first step.

- Third step: reimbursement in seven years from the date of the total reimbursement of the first step.

The plan is largely sustainable in 18 years, with wide margins of guarantee. According to this simulation, the objective of supporting the $100 \%$ costs of energy renovation with the savings obtained seems to be fully achieved. A feasibility assessment in the absence of the tax credit has also been performed to test the financial solution in other EU countries without incentives schemes. The plan proves to be largely sustainable in 27 years, with the following reimbursement plan: the first step as long as 22 years, the second step lasting ten years from the tenth year of the 
first step and the third step lasting seven years from the end of the second step. An analogous test (no incentives) was then carried out in the case of a single-stage intervention, resulting in a plan largely sustainable in 15 years (see Appendix §5.4), decreasing to eleven years if incentivized according to the actual Italian system.

\subsection{Application of the MedZEB Protocol}

- Retrofitting Design: To set the baseline for defining the savings targets, the energy performances of the building have been taken into account as the starting point before undertaking building retrofitting. The heating and cooling needs have been evaluated, as well as the energy needed for domestic hot-water. The carbon footprint of the building has also been assessed. Figure 6 shows the main results in terms of energy parameters and of $\mathrm{CO}_{2}$ emissions.

- Building Renovation Roadmap: It was planned over a period of 18 years, by scheduling three renovation steps. Several KPIs have been taken into account to assess not only energy performance, but also comfort and well-being. The HAPPEN cost-optimal POS was applied and evaluated; with reference to the energy aspects, the performances of the heating and cooling systems have been analyzed, as well as the energy produced by RES.

- Business Plan: It was designed in three steps over a period of 18 years, by basing on the VEL solution (for the application of the HAPPEN technical and financial solutions see $\S 3.1$ and $\S 3.2$ ).

- Voluntary Certification Scheme: it is issued at the end of each of the three steps. A specific rating system has been drafted to take into account the energy savings achieved for each renovation level, as well as for including comfort and well-being standards (see Fig. 7).

\section{Conclusions and Further Perspectives}

The paper illustrated a first positive assessment on the application of the MedZEB cost-optimal approach to a real case study; in particular, the potentialities of the approach were highlighted to pragmatically achieve deep renovation standards

\begin{tabular}{|c|c|c|c|c|c|c|c|}
\hline & $\begin{array}{c}\text { HEAT } \\
\left(\mathrm{kWh} / \mathrm{m}^{2}\right)\end{array}$ & $\begin{array}{c}\mathrm{COOL} \\
\left(\mathrm{kWh} / \mathrm{m}^{2}\right)\end{array}$ & $\begin{array}{c}\text { DHW } \\
\left(\mathrm{kWh} / \mathrm{m}^{2}\right)\end{array}$ & $\begin{array}{c}\text { PEC } \\
\left(\mathrm{kWh} / \mathrm{m}^{2}\right)\end{array}$ & $\begin{array}{c}\text { FEC } \\
\left(\mathrm{kWh} / \mathrm{m}^{2}\right)\end{array}$ & $\begin{array}{c}\text { Life Cycle } \\
\text { Cost } \\
\left(€ / \mathrm{m}^{2}\right)\end{array}$ & $\begin{array}{c}\mathrm{CO}_{2} \\
\text { Emissions } \\
\left(\mathrm{kg} / \mathrm{m}^{2}\right)\end{array}$ \\
\hline BASE & 139.31 & 3.46 & 16.23 & 187.68 & 176.49 & $806.09 €$ & 35.16 \\
\hline
\end{tabular}

Fig. 6 Energy performance of the building before retrofitting 


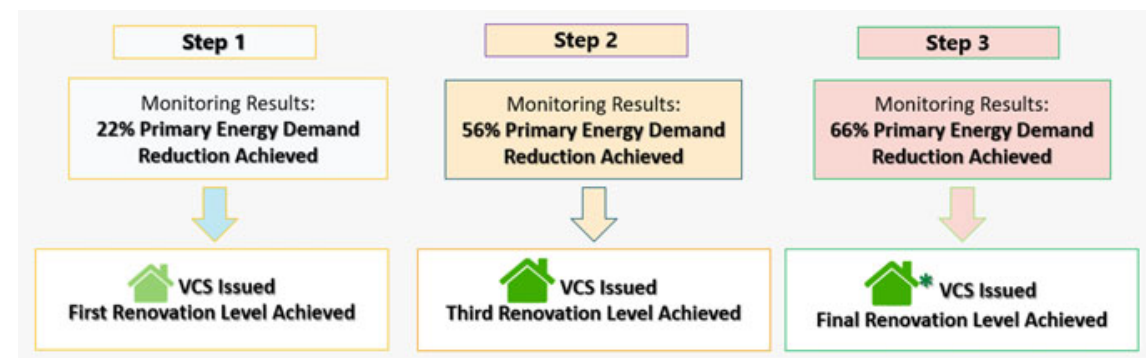

Fig. 7 Overview of the PEC reductions achieved after each step and of the VCS issued; the asterisk reported in the third step symbolizes the full achievement of energy and comfort objectives set in the MedZEB protocol

(above the threshold of $60 \%$ of energy savings, according to Fabbri et al. 2016) through a self-repayment mechanism for which intervention costs are largely sustainable through the economies generated by energy savings. The system looks robust, also considering the stress conditions introduced in the simulations, which enable one to consider the results obtained as conservative. In case of incentives (fiscal or cash incentives), payback times are further reduced in favor of all actors involved.

Further testing will be needed and extended over various climatic ranges, built typologies and regulatory situations of the Med area, also considering different technical and financial constraints, to allow generalizing these first results and outlining a complete exploitability field for the MedZEB approach. This will be done in the second part of the HAPPEN project, thanks to an extensive testing of the overall approach within the ten pilot sites identified across seven EU Med countries.

A crucial development will consist of designing a scoring system for evaluating non-energetic aspects, such as comfort and well-being, to foster positive decision making by offering substantial spillovers beyond the energy savings. To this extent, the final protocol should also include specific KPIs, such as bio-meteorologic indexes (e.g., Golasi 2016) tailored for the Med countries and will take into account the global use of natural resources in the retrofitting process.

Moreover, the HAPPEN platform has been co-designed through an active engagement of final users and partners in living laboratories environment, with the aim of becoming a common benchmark for the deep retrofitting markets in the EU Med countries. Future research activities in this field will be focused on transferring the project outputs into dedicated digital tools for owners, makers and influencers, with the aim of assisting them in the tailored and integrated application of the HAPPEN solutions, thus fostering the de-fragmentation and upgrade of the whole retrofitting supply and value chain.

This will also be done by activating in each partner country a "HAPPEN incubator," in which relationships among stakeholders will be promoted for all targeted groups, with the aim of developing a go-to-market strategy for the MedZEB approach, and of drafting a general business model for the widest and sustainable market uptake of the HAPPEN program. The ultimate objective of these incubators is turning the 
variegated retrofit markets of the EU Med area into a homogeneous market space, thanks to the adoption of a common approach specifically designed to overcome their current barriers, and to cope with local contexts in an adaptive and flexible way.

\section{Appendix: Technical Details of the Application to the Case Study}

\subsection{Technical Details of the Case Study Building}

The winter severity climatic index is 1.24 ; the summer severity climatic index is 0.62 according to the methodology proposed by Salmeron et al. (2013). Total useful surface is 1198.7 sq.m. Compactness, defined as volume to area ratio, is $2.96 \mathrm{~m}$ because the two lateral walls - east and south oriented-are party-wall in contact with other blocks. The north façade is glazed $6 \%$ while the south façade is $12 \%$ glazed. The global thermal transmittance (U-value) of the façades is $1.81 \mathrm{~W} / \mathrm{m}^{2} \mathrm{~K}$, the $\mathrm{U}$-value of the roof is $2.25 \mathrm{~W} / \mathrm{m}^{2} \mathrm{~K}$, the $\mathrm{U}$-value of the slab-on-grade is $1.75 \mathrm{~W} / \mathrm{m}^{2} \mathrm{~K}$ and the $\mathrm{U}$-value of the windows is $5.7 \mathrm{~W} / \mathrm{m}^{2} \mathrm{~K}$, giving an average $\mathrm{U}$-value for the whole building envelope weighted by the surface of each element of $2.54 \mathrm{~W} / \mathrm{m}^{2} \mathrm{~K}$. The heating needs of the building are $139.31 \mathrm{kWh}$ per sq.m. of useful surface (u.s.) and the cooling needs are $3.46 \mathrm{kWh} / \mathrm{m}^{2}$ of u.s. The heating and domestic hot-water system is a mixed gas boiler with a seasonal performance of 0.89 . The cooling system consists of a centralized heat pump per dwelling, with a seasonal energy efficiency ratio (SEER) of 2.0.

\subsection{Technical Details of the Overall Cost-Optimal Solutions}

\section{Building envelope:}

- Roof: Increase in thermal resistance of $2.35 \mathrm{~m}^{2} \mathrm{~K} / \mathrm{W}$, installing eight $\mathrm{cm}$ of XPS insulation on the outdoor surface of the roof. Investment of $3593.3 €\left(21.42 € / \mathrm{m}^{2}\right.$ of roof).

- Windows: Double glazing filled with argon. U-value of the whole window including frame of $2.7 \mathrm{~W} / \mathrm{m}^{2} \mathrm{~K}$, investment of $56,700.0 €\left(420 € / \mathrm{m}^{2}\right.$ window $)$.

- Façades: Increase in thermal resistance of $2.22 \mathrm{~m}^{2} \mathrm{~K} / \mathrm{W}$, using a ETICS with eight $\mathrm{cm}$ of EPS. Investment of 34,542.6€ (46.02 €/m² façade).

- Air-tightness: Reduction to an n50 value of $3 \mathrm{~h}^{-1}$ installing the new windows using an air-tightness system in the contour joints. Investment of 19,184.2€.

- Thermal bridges: Reduce the external psi-value of slabs-façades junctions from $1.25 \mathrm{~W} / \mathrm{mK}$ to $0.624 \mathrm{~W} / \mathrm{mK}$, and the external psi-value of windows contour from 0.589 to $0.05 \mathrm{~W} / \mathrm{mK}$. Total investment of $22,569.6 €$. 
- Installation of shadings that reduce the solar factor by a 50\%. Investment of 5616 $€(60 €$ per sq. m. of window)

Building systems:

- Controlled mechanical ventilation system, supplying 0.24 equivalent ACH, investment of $75,532.2 €(6294.4 €$ per dwelling).

- Heating production based in a new condensing gas boiler. Investment of 19,800€

- Domestic hot-water production based on aerothermal technology with a $50 \%$ of renewable energy contribution. Investment of 30,297.6€.

Building surroundings: Basing on the Solene project outputs, for this typology of intervention, glazing ratio and level of insulation, the optimum solution is to plant trees in the street (Morille et al. 2015).

\subsection{Technical Details of the Step-By-Step Cost-Optimal Solutions}

- First step: Improvement of the outdoor façades, windows and thermal bridges of windows contours. Initial investment of $132,996.4 €\left(110.8 € / \mathrm{m}^{2}\right.$ of useful surface). Primary energy consumption after the intervention of $146.2 \mathrm{kWh} / \mathrm{m}^{2}$, which is a reduction of $22 \%$ compared to the existing building, and implies an economic saving of $8923.6 € / \mathrm{yr}$.

- Second step: Installation of the insulation on the roof, the controlled mechanical ventilation system and the shading elements. Initial investment of 84,741.5€ ( $70.6 € / \mathrm{m}^{2}$ of useful surface). Foreseen primary energy consumption after the intervention of $82.36 \mathrm{kWh} / \mathrm{m}^{2}$, which is a reduction of $44 \%$ compared to the building after the first step renovation, and implies an economic saving of 14,226.4 $€ /$ yr.

- Third step: New condensing gas boiler and aerothermal domestic hot-water system with a $50 \%$ of RES contribution. Initial investment of $50,097.6 €\left(41.8 € / \mathrm{m}^{2}\right.$ of useful surface). Foreseen primary energy consumption after the intervention of $64.4 \mathrm{kWh} / \mathrm{m}^{2}$, which is a reduction of $22 \%$ compared to the building after the second step renovation, and implies an economic saving of $3903.5 € / \mathrm{yr}$.

\subsection{Technical Details of the Financial Solution}

Step-by-step approach, with Italian incentives applied only on the first step: 
- First step. Savings: $€ 8.900$ per year; reimbursement: eleven years; cost of the reimbursement: from $€ 7000.00$ in the first year to $€ 5900.00$ in the firth year, $€ 5000.00$ of the eight year, etc.

- Second step. Savings: $€ 14,200.00$ per year (to which the savings of the first step are added, reduced from $€ 3900$ to $€ 2500.00)$; total available financial resources $€ 16,700$; cost of the annual reimbursement $€ 13,500.00$; reimbursement: seven years from the date of the eight year of the first step.

- Third step. Savings: $€ 3900$ per year (plus the saving deriving from the end of the debit for the first step, estimated in $€ 4100$ ); available resources $€ 8000.00$; cost of the annual reimbursement $€ 7900$; reimbursement: seven years from the date of the total reimbursement of the first step; therefore, it is not necessary to recover also the savings of the second step that we consider as marked up to a guarantee.

Step-by-step approach, without incentives:

- First step. Savings: $€ 8900 /$ year; reimbursement: 22 years; cost of the reimbursement: €8262/year,

- Second step. Savings: $€ 14,200.00$ per year; cost of the annual reimbursement $€ 9840.00$; reimbursement: ten years from the date of the fifth year of the first step.

- Third step. Savings: $€ 3,900$ per year (plus the saving deriving from the end of the debit for the second step, estimated at $€ 4100$ ); available resources $€ 8000.00$; cost of the annual reimbursement $€ 7900$; reimbursement: seven years from the date of the total reimbursement of the second step; therefore, it is not necessary to recover also the savings of the second step that we consider as marked up to a guarantee.

Single-step approach, with Italian incentives:

Starting parameters: loan of $€ 270,000.00$ for eleven years, with a fixed rate $3 \%$; maximum financial commitment: $€ 14,322.00 /$ year (about $57 \%$ of the prudentially estimated savings of $€ 25,000.00 /$ year).

Single-step approach, without incentives:

Starting parameters: loan of $€ 27,000.00$ for 15 years, with a fixed rate $3 \%$; 180 monthly payments of $€ 1865.00$, equal to $€ 22,380.00 /$ year (about $89 \%$ of the prudentially estimated savings of $€ 25,000.00 /$ year).

Acknowledgments This project has received funding from the European Union's Horizon 2020 research and innovation programme under grant agreement No 785072. 


\section{References}

Antonucci D (2019) EURAC, Key Performance Indicators (KPIs) and needed data. D3.1, ExCEED Project, H2020, G.A.723858

Asdrubali F (2017) Isola della sostenibilità. Gli edifici ad energia zero. Conference, Università degli Studi Roma Tre, Rome

Becchio C, Dabbene P, Fabrizio E, Monetti V, Filippi M (2015) Cost optimality assessment of a single family house: building and technical systems solutions for the nZEB target. Energy Buildings 90:173-187

BPIE (2010) Cost optimality. Discussing methodology and challenges within the recast Energy Performance of Building Directive. BPIE Document. Accessed Jan 2020 https://bpie.eu/wp-con tent/uploads/2015/10/BPIE_costoptimality_publication2010.pdf

BPIE (2014) Energy Performance Certificates across the EU. BPIE Document. Accessed Jan 2020. https://bpie.eu/publication/energy-performance-certificates-across-the-eu/

Brandao A, Duarte M, Manso A, Cabaço A (2016) EPBD cost-optimal methodology: application to the thermal rehabilitation of the building envelope or a Portuguese residential building. Energy Buildi 111:12-25

Caceres AG, Diaz M (2018) Usability of the epc tools for the profitability calculation of a retrofitting in a residential building. Sustainability 10(9):3159

Directive (EU) 2018/844 (2018) Amending Directive 2010/31/EU on the energy performance of buildings and Directive 2012/27/EU on energy efficiency. Accessed Jan 2020. https://eur-lex.eur opa.eu/legal-content/EN/TXT/?uri=uriserv\%3AOJ.L_.2018.156.01.0075.01.ENG.

EuroPHit (2015) Criteria for EU-wide step-by-step energy efficient refurbishment including RES. EuroPHit project, D2.1, IEE, G.A. SI2.645928

Fabbri M, De Groote M, Rapf O (2016) Building Renovation Passports. Customized roadmaps towards deep renovation and better homes. BPIE documents. Accessed Jan 2020. https://bpie.eu/ wp-content/uploads/2017/01/Building-Passport-Report_2nd-edition.pdf

Golasi I, Salata F, de Lieto VE, Coppi M, de Lieto VA (2016) Thermal perception in the Mediterranean area: comparing the Mediterranean Outdoor Comfort Index (MOCI) to other outdoor thermal comfort indices. Energies 9:550

Hamelman, J. (2016). A comparative analysis of certification schemes. Bachelor Thesis, University of Twente, the Netherlands.

Kudryashova A, Genkov A, Mo T (2015) Certification schemes for sustainable buildings: assessment of BREEAM, LEED and LBC from a strategic sustainable development perspective. Thesis submitted for completion of Master of Strategic Leadership towards Sustainability, Blekinge Institute of Technology, Karlskrona, Sweden

Mattoni B, Guattari C, Evangelisti L, Bisegna F, Gori P, Asdrubali F (2018) Critical review and methodological approach to evaluate the differences among international green building rating tools. Renew Sustain Energy Rev 82(1):950-960

Morille B, Lauzet N, Musy M (2015) SOLENE-Microclimate: a tool to evaluate envelopes efficiency on energy consumption at a district scale. Energy Proc 78:1165-1170

Padula M, Picenni F, Malvezzi R, Laghi L, Salmeròn JM, Sanchez FJ, Mateo-Cecilia C, SotoFrancés L, Assimakopoulos MN, Karlessi T (2018) MedZEB: a new holistic approach for the deep energy retrofitting of residential buildings. TECHNE—J Technol Archit Environ 1:127-133 (Special Issue)

Salmeron JM, Álvarez S, Molina JL, Sánchez FJ (2013) Tightening the energy consumptions of buildings depending on their typology and on Climate Severity Indexes. Energy Build 58:372-377

Sesana MM, Salvalai G (2018) A review on building renovation passport: potentialities and barriers on current initiatives. Energy Build 173:195-205

Consulting TE (2014) Market Study for a voluntary common European Union Certification Scheme for the Energy performance of non-residential Buildings. Final Report, Appendix C 
Open Access This chapter is licensed under the terms of the Creative Commons Attribution 4.0 International License (http://creativecommons.org/licenses/by/4.0/), which permits use, sharing, adaptation, distribution and reproduction in any medium or format, as long as you give appropriate credit to the original author(s) and the source, provide a link to the Creative Commons license and indicate if changes were made.

The images or other third party material in this chapter are included in the chapter's Creative Commons license, unless indicated otherwise in a credit line to the material. If material is not included in the chapter's Creative Commons license and your intended use is not permitted by statutory regulation or exceeds the permitted use, you will need to obtain permission directly from the copyright holder.

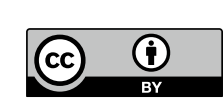

